Revista de la red interuniversitaria de estudios sobre las literaturas rioplatenses contemporáneas en Francia

11 | 2014

De niños e infancias

\title{
Escribir del padre
}

\section{Álvaro Bisama}

\section{(Q) OpenEdition \\ Journals}

\section{Edición electrónica}

URL: http://journals.openedition.org/lirico/1876

DOI: 10.4000/lirico.1876

ISSN: 2262-8339

Editor

Réseau interuniversitaire d'étude des littératures contemporaines du Río de la Plata

\section{Referencia electrónica}

Álvaro Bisama, «Escribir del padre », Cuadernos LIRICO [En línea], 11 | 2014, Publicado el 01 diciembre 2014, consultado el 22 septiembre 2020. URL : http://journals.openedition.org/lirico/1876 ; DOI : https://doi.org/10.4000/lirico.1876

Este documento fue generado automáticamente el 22 septiembre 2020.

\section{(c) (i) (9)}

Cuadernos LIRICO está distribuido bajo una Licencia Creative Commons Atribución-NoComercialSinDerivar 4.0 Internacional. 


\section{Escribir del padre}

Álvaro Bisama

REFERENCIA

Mi libro enterrado, Mauro Libertella, Buenos Aires, Mansalva, 2013, 77 p. 
El año 2001, el cronista chileno Francisco Mouat editó un libro llamado El empampado Riquelme que investigaba la desaparición de un hombre en el desierto a mitad de la década del 50 y el descubrimiento, varias décadas después, de sus osamentas en medio de la pampa. Julio Riquelme, a quien pertenecían esos restos, viajaba desde Chillán al bautizo de uno de sus nietos en Iquique, pero por una razón desconocida -la búsqueda de esa razón es uno de los ejes de la escritura de Mouat- se bajó del tren que lo llevaba y se perdió en la pampa. Nunca llegó a destino. El libro de Mouat trata su caso entrecruzando su vida posible con la descripción de su entierro tardío, además de detallar las culpas familiares detonadas por su ausencia. El libro, que parte como una investigación periodística, luego cobra una forma mutante, extraña. Al

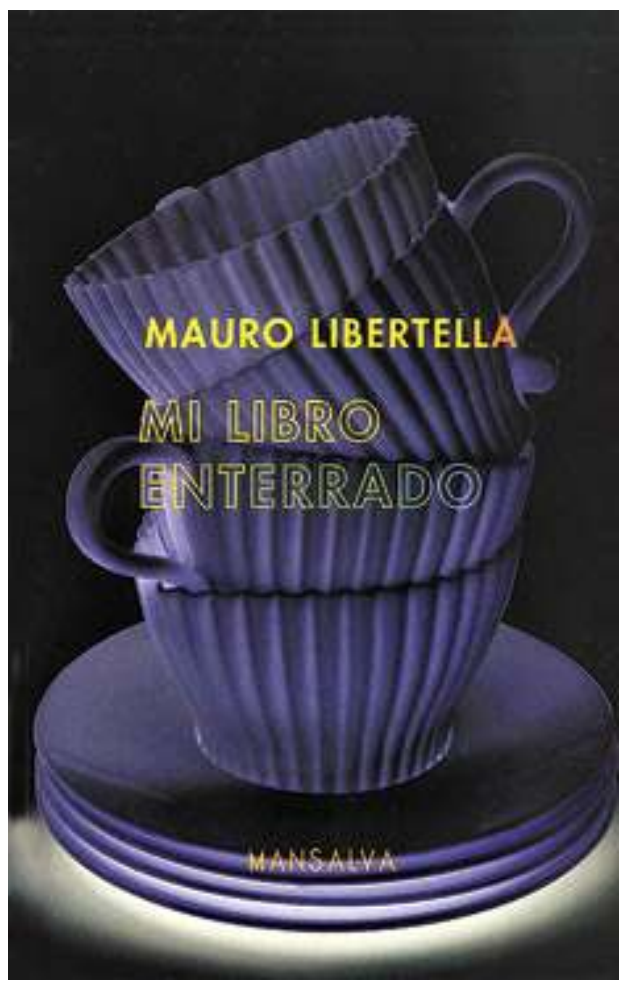
final, el caso quedaba abierto y temas como la desaparición del padre y los modos del luto se vuelven un espejo para las inquietudes del autor. Porque a Mouat, Julio Riquelme lo obliga a examinar la relación con su propio padre, convirtiendo aquel lazo en una medida con la que juzgar al mundo. Así, el libro escapa al mero relato de una historia individual (la idea de un caso que se resuelve, que se puede explicar), para convertirse en una suerte de metáfora de una identidad colectiva: los huesos de Riquelme, perdidos y encontrados, terminan aludiendo a la historia chilena de la segunda mitad del siglo XX, esbozando una tragedia hecha de cuerpos sin sepultura.

2 La última edición, lanzada el año 2012 por la propia editorial del autor (Lolita), supone también una reescritura que aspira a ser la versión final del relato. En ella, el libro encuentra ciertas zonas de diálogo con otras obras como Vas a extrañarlo porque es justo, del periodista argentino Daniel Riera, también editado por Lolita, sello que trabaja con singular sutileza el tema de la memoria. Texto brevísimo, se enlaza con el libro de Mouat no solo en la colección sino con el tono. En él, Riera describe los últimos días de su padre, dueño de una distribuidora de libros y protagonista de una serie de negocios fallidos, todos depredados por la realidad argentina de las últimas cuatro décadas.

3 Pienso en esos dos libros como un contexto posible para leer Mi libro enterrado, el volumen donde Mauro Libertella (1983) repasa los últimos días de la vida de su padre Héctor, devastado por el alcohol y la enfermedad. Que se trate de Héctor Libertella (1945-2006), sobre el que se ha erigido una densa red de lecturas e interpretaciones (con el volumen El efecto Libertella, del año 2010, como un resumen de las mismas ${ }^{1}$ ) solo aumenta la condición demoledora del texto, que es a la vez una despedida y un mapa, un perfil que evita toda complacencia en el relato de esos días terminales, pues el padre es un espejo del hijo que lo narra, relatándose, con eso, también a sí mismo. Anota Mauro Libertella : “Tenía 23 años, la edad exacta en que mi viejo publicó su primer libro 
y recibió su primer premio literario importante (...) Yo ya había llegado a esa edad, y nada. Un año antes viví apuntalado por ese apuro, y la edad se iba erigiendo como un agujero negro. Los 23 eran, de algún modo, y por anticipado, mi edad síntoma. Porque esa había sido la edad de su despegue ; el momento en el que se publicó su primer libro ; recibió miles de billetes, se fue de viaje por el mundo y al volver se mudó a Buenos Aires. A los 23 años él tuvo su primera novela y yo tuve su muerte" (44-45).

4 Quizás este fragmento sea una pequeña síntesis del libro, que une la brevedad con la precisión pero también la tensión de hacerse cargo de una tarea impuesta, del peso de la propia biografía puesta en abismo ante la narración de otro relato, el del padre. La escritura (que podríamos catalogar de "testimonio") está construida casi por una especie de mandato : la pregunta por la vida del padre tiene un efecto especular, es también la interrogación sobre cómo escribir sobre ella.

5 En ese sentido, habría que leer Mi libro enterrado como un modo de despejar de todo ruido (el ruido de la interpretación, el ruido de la anécdota, el ruido de la memoria de los amigos, el ruido de los lectores y discípulos) la lectura de Héctor Libertella. La opción del hijo es la del retorno a un territorio básico, que carece de cualquier especulación posible, como si el gesto elegíaco fuera deconstruido desde la intimidad. De este modo, si la obra de Héctor Libertella cuestiona de modo constante cualquier forma de legibilidad para codificar una literatura desplegada en el hermetismo como política de lectura, una política que trata de establecer los secretos vinculantes que pueden construir una comunidad (la literatura para Libertella es, quizás, una suerte de santo y seña en perpetua reelaboración de sus alcances), la memoria que hace su hijo se escribe desde la claridad desoladora del relato de la experiencia de la enfermedad y del duelo. Es como si el hijo quisiese eliminar la dificultad de la interpretación y devolver la vida a la obra del padre, evitando los intermediarios (el cénacle donde suenan los gritos de guerra, al decir de Walter Benjamin) o, mejor dicho, replanteando su relación con ellos como si fuera un pacto que se renueva.

6 Anota: "Cuando mi padre murió, empecé a circular por los lugares donde sabía que estaban sus amigos, buscándolos. La sensación que me provocaban esos encuentros era ambigua : me hacían mal pero los necesitaba. [...]. No los juzgo, pero yo quedaba muy cargado después de esas charlas, a veces destruido. Me hacía bien, sin embargo, reconstruir el rompecabezas de lo que había sido mi viejo para otra gente y en otros ámbitos. Eran relatos que me abrían la herida al mismo tiempo que me la suturaban. Así estuve por muchos meses, yendo y viniendo, fascinándome sin darme cuenta del todo con sus amigos de los años más terribles, los del alcohol y la muerte lenta. Hasta que el recuerdo maceró y ellos dejaron de ser una amenaza y una necesidad, para pasar a ser los amigos de mi viejo" (39-40)

7 La eficacia de ese gesto (que es biográfico pero también crítico) descansa en el hecho de que la escritura de Mauro Libertella es sospechosamente traslúcida. El estilo ha sido limpiado de todo elemento accesorio, de cualquier cosa que desvíe la mirada de lo que se está narrando. En una novela de ficción, esto sería simplemente un artificio narrativo. En Mi libro enterrado se vuelve un imperativo moral. La precisión escritural evita cualquier ambigüedad colocando aquella transparencia como algo ineludible. Ahí reside el valor del libro, que desea restarse de cualquier tradición y aspira a ser leído desde la intimidad de un exorcismo privado. Libertella rescata a su padre de sus exégetas, de sus amigos y de sus lectores. Lo oculta colocándolo a la luz del mundo, 
describiendo "los años terribles" y los avances de la enfermedad y la pérdida de la conciencia hasta llegar al momento de la muerte.

8 Con esto, repostula el lazo de él mismo con la tradición, que concluye en sí mismo y en su libro. El sentido de lo anterior descansa en hacer ingresar lo individual en lo colectivo porque, quizás, la pregunta que ronda Mi libro enterrado es: ¿qué es la tradición ?, ¿cómo relacionarse con ella?¿cómo leerla sino como un movimiento íntimo, familiar?

9 No es raro que en algún momento, sobre el final, el narrador confiese que está obsesionado con "la lectura de novelas y relatos sobre la muerte del padre". Anota, además: "Como en una cinta de Moebius, esos relatos se encadenaban en una lógica espiralada que amenazaba con absorberme para siempre. Todos esos relatos son únicos [...] al tiempo que están condenados a la universalización" (65-66). "Esos libros erigen una relación curiosa con el modo de leer. Un poco a mitad de camino, se leen por dentro y por fuera de la literatura" (66).

10 Se trata de un gesto lleno de significados. Mi libro enterrado contempla el modo en que va a ser leído, volviéndose sobre su propio género de pertenencia, que incluye a Kafka y Roth, pero también a los mencionados Riera o Mouat. Esto tiene cierto sentido. Décadas antes, en el lapso que va de los años sesenta a la primera década de este siglo (de la revista Literal a Arquitectura del fantasma, del 2006), Héctor Libertella había respondido a esa pregunta (¿cómo se configura la tradición ?) tratando de establecer una lista de lecturas, una "librería" posible que tomaba la forma de una investigación sobre el significado de la escritura y cómo esta configuraba un código común de reconocimiento entre los miembros de una comunidad. Ahí, los autores comentados en Nueva escritura en Latinoamérica ${ }^{2}$ no funcionaban solo como un contracanon o una estocada al imperio del Boom sino como la constitución de un horizonte de identidades posibles construidas por oposición a una norma (la de la novela total que era la utopía demencial que venía de los sesenta), relacionadas entre ellas solo por la mirada de Libertella, zurcidas en un espacio común en el ensayo antes mencionado, que era un ejercicio de hilado de una ficción sobre los modos de leer en el continente.

11 Cuando Mauro Libertella escribe sobre su padre, esa comunidad ya se ha establecido, Es un mapa literario y geográfico donde habitan "César" y "Ricardo", por ejemplo ; un mapa que es el centro del debate que Damián Tabarovsky propone en Literatura de izquierda, y que se despliega en la lista de lecturas recomendadas por Roberto Bolaño en "Derivas de la pesada. Se trata del trazado de una serie de desplazamientos sobre una ciudad (el departamento del padre, el bar Varela Varelita, el hospital, etc.) que es el reflejo de una vida. Así, el libro es la confirmación de un mapa, pero también el modo de moverse del hijo por un paisaje que es literario pero también físico ; de andar en una ciudad que ha quedado vacía porque su padre ha muerto.

12 Esto quizás se deba a que el aporte de Héctor Libertella a la tradición -el lugar donde quizás descansa la mitología construida en torno a su figura- es el hecho de sugerir un modo de leer, un método, un sistema para organizar y destrabar una biblioteca y plantearse el acto mismo de la escritura. En Mi libro enterrado eso cobra importancia en el momento en que el hijo resume cómo el padre lo lee, siguiéndolo a través de los textos que va publicando en la prensa cultural de Buenos Aires: "Promediando el segundo año de la carrera empecé a publicar mis primeros textos periodísticos en un diario. Mi padre leía todo lo que yo publicaba y casi siempre me devolvía algún elogio preciso pero medido [...] en esas primeras lecturas enfatizaba la 'claridad' de mi 
escritura [...] Yo sin embargo no lo creía. Me preguntaba cómo alguien que predicó durante décadas la pureza de la forma hermética, iba a recortar como mérito central de un texto su carácter transparente" (42).

13 Por lo mismo, hay una especie de tensión en esa distancia : la sospecha de no estar a la altura -la neurosis de cumplir el mandato- de la lectura del padre, que se resuelve en un momento significativo : leyendo una nota del hijo sobre el fallecimiento de Syd Barret, el líder original de Pink Floyd, el padre comienza a llorar. Anota Mauro Libertella : "el llanto fue corto y profundo ; hacía mucho que no lo veía llorar ; y diría que fue una de las pocas veces en mi vida en que lo vi quebrarse" (43).

14 Es complejo pero conmovedor: la angustia de la influencia se resuelve acá como un lazo privado, como un modo de continuidad. Es un gesto intencionado de filiación, como si Mi libro enterrado completara los múltiples espacios en blanco que aparecen en Arquitectura del fantasma, la autobiografía de Libertella padre, al modo de interrupciones y cortes que ponen atención sobre lo complejo del racconto de la propia vida, una tarea que se le presenta de modo irresoluto pero también paródico.

15 Mi libro enterrado se escribe sobre esos espacios vacíos : el hijo completa el libro del padre pero también desvía su lectura, apropiándose del relato. Reordena la librería argentina como si fuese un lugar en el que volver a habitar. A diferencia de Kafka o Roth, autores modélicos en el tema, lo que acá hay no es una distancia (la escritura de Kafka como un reemplazo de los roles familiares que nunca cumplirá, según anota en la célebre carta a su padre) o una epifanía (la escena de la piscina en Patrimonio) sino la construcción de un espacio de continuidad. Ahí, la tradición se transforma en algo más concreto, excede la biblioteca y está y no está dentro de la literatura : la relación de un padre con un hijo, el mapa de un barrio, el detalle de los días finales de un moribundo, el relato de una vida. La escritura del duelo funciona estableciendo un lazo, escribiéndose desde lo no dicho (el hijo escribe desde las elipsis de la escritura del fantasma del padre), haciendo que Héctor Libertella deje de hablar por medio de las interpretaciones de los otros para unirse a la voz de su hijo, para ser su hijo.

\section{NOTAS}

1. M. Damiani (comp.), El efecto Libertella, Buenos Aires, Beatriz Viterbo, 2010.

2. H. Libertella, Nueva escritura en Latinoamérica, Caracas, Monte Ávila, 1977. 


\section{AUTORES}

ÁLVARO BISAMA

Universidad Diego Portales 